\title{
Artelogie
}

Recherche sur les arts, le patrimoine et la littérature de I'Amérique latine

16 | 2021

Fotografía y migraciones, siglos XIX-XXI.

\section{Superficies proyectadas, migraciones estéticas y abstracción fotográfica en la obra de Sameer Makarius}

Juliana Robles de la Pava

\section{OpenEdition}

Edición electrónica

URL: https://journals.openedition.org/artelogie/9182

DOI: 10.4000/artelogie.9182

ISSN: 2115-6395

Editor

Association ESCAL

\section{Referencia electrónica}

Juliana Robles de la Pava, «Superficies proyectadas, migraciones estéticas y abstracción fotográfica en la obra de Sameer Makarius», Artelogie [En línea], 16 | 2021, Publicado el 27 enero 2021, consultado el 03 septiembre 2021. URL: http://journals.openedition.org/artelogie/9182 ; DOI: https://doi.org/ $10.4000 /$ artelogie.9182

Este documento fue generado automáticamente el 3 septiembre 2021.

Association ESCAL 


\title{
Superficies proyectadas, migraciones estéticas y abstracción fotográfica en la obra de Sameer Makarius
}

\author{
Juliana Robles de la Pava
}

\section{Introducción}

1 La fotografía como modo de producción de visualidades técnicas nos ha dejado en claro, desde su nacimiento en la primera mitad del siglo XIX, que no consiste en una forma única o univoca de producción fotosensible (Kriebel, 2006: p. 3). En este sentido, la fotografía constituye una materialidad diversa y multiforme, incapaz de ser reducida a una totalidad homogénea. La proliferación de prácticas fotográficas ha estado acompañada, en los últimos siglos, por innumerables discursividades que validan su constitución como huella, ${ }^{1}$ registro o instantaneidad mecánica. Más allá de estas aproximaciones este trabajo pretende definir y analizar a los proyectogramas de Sameer Makarius, producidos en la década del 50 en Argentina, como materialidades fotográficas vibrantes (Bennett, 2010) que no son solo portadoras de significados, sino que los generan por medio de operaciones de morfogénesis propias de la materialidad (Witzgall, 2014: pp. 14-15) fotográfica [Figs. 1 y 2]. Esto significa que la fotografía, en tanto modo de producción y concepción de un determinado tipo de objetos fotográficos, porta como facultad la capacidad de autoproducir significados y cualidades específicas que no son solo una prerrogativa del fotógrafo o artista de cuya actividad son el resultado. Este modo de comprensión de lo fotográfico, inscripto dentro de las concepciones sobre la materia propuestas por los nuevos materialismos, busca su aplicación en un modo de pensar las materialidades artísticas como actantes de una red de sentidos y deseos mucho más extensa que aquella formulada bajo la lógica de lo específicamente humano. Conforme a esta aproximación, se hace lícito pensar que los interrogantes formulados por este artículo no se encuentran dirigidos de 
modo exclusivo y excluyente a la figura de Makarius como agente de los tránsitos estéticos de sus fotografías, sino a las fotografías mismas como portadoras, en su materialidad, de los recorridos visuales para los cuales la experiencia migratoria de su productor es solo una marca entre muchas otras.

2 Algunas de las capacidades autopoiéticas (Iovino y Oppermann, 2018: p. 216) develadas por las fotografías tienen que ver, en parte, con los procedimientos específicos desarrollados en la historia técnica del medio, pero también, con las interrelaciones sensibles que la fotografía ha entablado con diversas tradiciones estéticas. En este caso, con la abstracción como modalidad de comprensión de las producciones artísticas. Es así como a la par del desarrollo de la retícula modernista (Krauss, 2009: p. 23), se emprendió un recorrido insistente de producción de formas fotográficas abstractas que entablaron un diálogo con los presupuestos de la teoría de la abstracción pictórica.

3 Los sentidos desatados por parte de las materias fotográficas de los proyectogramas operaron entonces en distintos niveles superpuestos, materialmente, sobre una superficie. Plegados de una manera compleja en las texturas visuales de las fotografías, los tránsitos de la constitución objetual y artística de estas visualidades técnicas desatan una conceptualización particular de la materialidad fotográfica y su manera de operar como agente de significados propios. El universo teórico que nos permite construir este modo de funcionamiento de lo fotográfico es aquel propuesto en la filosofía deleuziana y su relectura de la teoría leibniziana del pliegue. Una figura material y temporal que contiene lo múltiple (Deleuze, 2014: p. 11).

Los trayectos de movilización de Makarius implicaron la navegación por un escenario social y cultural atravesado por la transformación constante de las apreciaciones al respecto de las artes, la técnica y la percepción estética. Tal como el artista cruzó por distintas instancias que motivaron la modificación de su concepción al respecto de la función y el lugar del arte en la cultura, sus proyectogramas abrazaron el deseo de transformación y hoy nos dejan ver un paso migratorio intercultural que les pertenece como propiedad fotográfica, además de la propia traza lumínica de la fotografía que puede ser a su vez entendida en un sentido migratorio. En este sentido, mas que tratarse de una migración humana, los proyectogramas develan las instancias de una migración estética y objetual que se encarnó en la forma de comprender la fotografía abstracta difundida luego, con muchos matices, por el escenario suramericano. Se trató, por lo tanto, de experiencias sensibles y objetuales que sufrieron la desterritorialización (Deleuze y Guattari, 2004) y que se objetualizaron en las apuestas proyectivas difundidas en la Argentina de los 50. Dichos desplazamientos estéticos, adheridos y transformados al modo de signaturas sobre los objetos fotográficos de Makarius, parecen haber puesto en evidencia una concepción migratoria que no se ciñe a los tránsitos culturales pensados en demasía desde la excepcionalidad del artista, sino a la vida migratoria del objeto. Aquella vida social de las cosas (Kopytoff, 1991: p. 89) y de las ideas sobre las cosas, que solo puede ser advertida en las cosas mismas. Por consiguiente, los proyectogramas emergieron de una tensa relación entre la vida de esos objetos e imágenes migrantes corporalizadas en ellos y de una experiencia migratoria humana que, sin duda, no puede ser soslayada. De tal modo, la idea de una migración estética, explicitada en las obras de Makarius aquí analizadas, pone en escena los recorridos de los objetos, las ideas, las poéticas, las discursividades y las visualidades que señalaron la constitución de los proyectogramas como materialidades dinámicas y abiertas. Desde esta óptica, la materialización fotográfica puede ser entendida como un 
proceso complejo, plural y relativamente abierto en el cual Makarius solo se vería inmerso entre las contingencias productivas de la propia materialidad fotográfica (Coole y Frost, 2010: p. 7). Atravesados por los itinerarios migratorios del artista, los proyectogramas pueden devenir, en esta lectura, materialidades migrantes. Su constitución: visual, formal, técnica, estética, social y material corporeiza dichos recorridos devenidos en el objeto en dimensiones heterogéneas (Deleuze y Guattari, 2004: p. 354) reconocibles en la superficie fotográfica. Por este motivo, las experiencias en la Europai Iskola, los vínculos con la abstracción concretista suiza y con ciertas formas visuales distanciadas del documentalismo de Bischof, nos permiten advertir la experiencia estética migrante encarnada en la sensibilidad material de los proyectogramas. Estas instancias migratorias serán aquí analizadas como dimensiones espaciotemporales; pliegues en los cuales se despliega la capacidad de agencia de las instancias materiales que constituyen a estas obras. Aquí no solamente se piensan las materias fotográficas que les dieron origen -luz, papeles y químicos- como componentes de su constitución objetual, sino también las marcas estéticas de una poética tangible de los objetos, alterada por los contactos y los encuentros con experiencias estéticas otras. Dichos recorridos serán analizados en los apartados de este artículo como instancias de objetivación material de estas obras de Makarius.

\section{La constitución mínima de la forma: la Europai Iskola}

5 Uno de los desarrollos centrales que caracterizó los modos de producción del abstraccionismo húngaro entre las décadas del 20 y el 30 estaba asociado a la superposición de las formas geométricas primarias como un modo de reordenar la experiencia sensorial involucrada en cierta lógica científico-tecnicista. La apuesta de esta mirada se direccionaba hacia aquellas formas simples que suponían una reorganización sensible a partir de los componentes estructurales con los cuales se hacía posible pensar la totalidad del espacio medible y calculable. La utilización de estos recursos visuales y compositivos no estaba sin embargo atada a un deseo de autonomización de las formas plásticas, sino que, más bien, se encontraba motivada por una emulación maquínica, sistemática, reiterada, económica -en términos visuales- y simplificadora. El humor que animaba la transformación de este enfoque constructivista de las obras producidas en el marco de la Europai Iskola en Budapest estuvo permeado por un sentimiento de transformación radical de las condiciones del sujeto moderno, inscripto en el acelerado desarrollo tecnológico y en las utopías de una transformación radical de los medios de producción en manos del proletariado. Este deseo revolucionario de transformación del orden social se hizo patente en los modos a partir de los cuales se constituyó el discurso de una práctica estético-artística que emprendió, a pesar de los deseos de sus actores, un camino independiente. Surgido en la Rusia soviética y diseminado por distintos países europeos, el constructivismo instituyó una orientación materialista del trabajo estético que permitiría, en este imaginario, concebir otras estructuras formales y lógicas de producción que dieran cuenta de un conjunto de cualidades propias o específicas de los materiales empleados.

De acuerdo con el programa productivista, firmado por Aleksandr Ródchenko y Varvara Stepánova -en el cual se describían los objetivos de la obra materialista constructiva- se afirmaba que: 
7 "El grupo designa como "factura" la materia escogida y utilizada efectivamente, sin plantear obstáculo alguno al progreso de la "construcción" o limitar la "tectónica". Entre los elementos materiales conviene citar los siguientes: 1. La materia en general: reconocimiento de su origen, de sus transformaciones en la industria y en la producción; su naturaleza y su significación [y] 2. Los materiales intelectuales: luz, plano, espacio, color, volumen. Los constructivistas tratan en el mismo plano ambos materiales" (González García, Calvo Serraller y Marchán Fiz, 2003: pp. 305-306)

8 Dichas declaraciones al respecto de la obra constructivista, y de la primacía de cierta forma de comprensión de la materia y la materialidad en estas producciones, se convirtieron también en moneda corriente al interior de escenarios parcialmente marginales con respecto de los centros hegemónicos del desarrollo de las vanguardias a principios del siglo XX. Este fue, precisamente, el caso de la Europai Iskola fundada entre 1945 y 1948 por Imre Pán (Durozoi, 1997: pp. 215-216) y a la cual asistió Makarius durante su estadía en Budapest a mediados de los 40.

Uno de los principios centrales que se ponían de manifiesto en las obras producidas en el marco de esta asociación de artistas tuvo que ver con el énfasis material que se hacía de la superficialidad pictórica. Sobre ésta no se enaltecía un principio de habilidad subjetiva que daba a la materia una forma, espiritualizándose la facticidad mas concreta de los materiales, sino que, en cierto sentido, se enfatizaba la cualidad morfogenética de los materiales y la impersonalidad que implicaba otorgarle a la materia y a las formas simples un lugar dentro de la producción estética moderna. Estos principios, asociados a la noción de faktura ${ }^{2}$ descripta y comentada por los intelectuales y artistas constructivistas, habilitó un nuevo interés en la superficie del plano como instancia de reinscripción de los poderes de una materia que lograría, incluso, modificar distintas lógicas de comprensión al interior de una sociedad revolucionaria. Según estas posiciones, la faktura implicaba un modo de concepción en el cual materia y construcción se veían compaginadas para la reordenación de la experiencia. De acuerdo con esto, Nikolai Tarabukin afirmaba en 1916 que "La forma de una obra de arte se deriva de dos premisas fundamentales: el material o medio (colores, sonidos, palabras) y la construcción a través de la cual se organiza el material en un todo coherente para que adquiera una lógica artística y un sentido profundo" (Citado en Buchloh, 2004: p. 122). Dejando de lado ese sentido profundo señalado por Tarabukin, se hace manifiesta la relevancia otorgada a la conjunción materia, medio y construcción como premisas a partir de las cuales concebir la posibilidad de la producción estética. En esas potencialidades de la materia y en su relación con una voluntad constructiva, emergía entonces la posibilidad de confeccionar un objeto artístico en el cual la capacidad subjetiva no se sobreponía a la material, sino que, como lo mencionaban Ródchenko y Stepánova, esos elementos materiales eran tratados en el mismo plano por el artista constructivista.

Recuperar estos principios que movilizaron diversas producciones en el marco de la Europai Iskola para analizar los tránsitos estéticos devenidos en los proyectogramas de Makarius, permite advertir la trashumancia de las nociones sobre la materia en el arte de las cuales hizo parte el periplo migratorio de la abstracción fotográfica luego desarrollada en el continente americano. ${ }^{3}$ Décadas después a la formulación de muchas de estas ideas, la composición de materias simples sobre planos vidriados de distintas dimensiones dio lugar a objetualidades que evidenciaban esta apuesta materialista. En una insistencia sobre la superficie como lugar de inscripción de transformaciones propias de las materias dispuestas -recortes de papel, pegamentos, materias orgánicas, 
inorgánicas etc.-, los proyectogramas hicieron visible y tangible una transmutación material e histórica que devino en planos texturados y proyectados a partir de transformaciones mediales [Fig. 3]. Desde las placas vidriadas que conformaron los positivos proyectados, hasta las proyecciones propiamente dichas de la luz reflejada sobre estas superficies, los proyectogramas dejaron en evidencia que la insistencia en la transformación constante de las materias generaba una nueva objetualidad. Esta se encontraba atravesada, en sus marcas texturadas, por la concepción estética de la faktura que se reinscribía -en sus notas aparentemente más simples- en el medio fotográfico casi cuarenta años más tarde.

11 Este modo de exposición de las ideas constructivistas reveladas por las materias fotográficas de Makarius, en gran medida ya radicado en la Argentina durante los cincuenta, dan cuenta de una temporalidad propia de la materia en conjunción con las ideas estéticas formuladas décadas antes. En este punto sería posible preguntar ¿en qué sentido los proyectogramas elaborados casi cuarenta años después de las formulaciones constructivistas hicieron sin embargo explícita una concepción de la materia similar?

12 Lejos de afirmar un dejo de influencia, las composiciones y concepciones de la superficie material de los proyectogramas hicieron evidente una constitución mínima de su forma que tuvo que ver con los pasajes y recorridos de estas poéticas y estéticas constructivas a través de un modo de interacción solo experienciable en su fisicalidad objetual. Por este motivo, la temporalidad de estos modos de pensar la materia, sus cualidades transformativas y significantes, excedió los movimientos de Makarius por distintos contextos artísticos haciendo patente una supervivencia de apreciaciones estéticas que son efectivamente comprensibles en las marcas, gestos de las formas y componentes de los propios proyectogramas.

\section{El máximum de la fuerza expresiva: vínculos con el concretismo y la deriva bauhausiana}

Luego de una salida apresurada de Budapest Makarius viajó a Suiza, lugar donde se vinculó con el artista y arquitecto Max Bill. La apuesta estética del concretismo se había sustentado sobre los presupuestos de precisión y claridad que habían definido la conciencia cientificista y tecnicista de producciones como las realizadas por Theo van Doesburg a principios de la década del 20 (De Micheli, 2012: p. 248). A diferencia de la mirada radicalmente revolucionaria que se hacía más explícita en los escritos constructivistas, la apuesta concretista parecía redefinir su campo de acción, casi netamente, en la consistencia en el uso de los medios de producción con los cuales los artistas definían su trabajo. Durante la segunda mitad de la década del cuarenta la producción artística de Makarius estaba casi completamente signada por el trabajo pictórico que constituía, en la tradición artística, un modo de elaboración estética privilegiado. En el marco de las apuestas de vanguardia en este contexto, la obra de Makarius vio empero aparecer un conjunto de procedimientos que apuntaban al mecanicismo como modo a partir del cual era posible pensar otra lógica de producción distanciada de los preceptos de la genialidad creativa. Con esta retórica que se veía enaltecida en conceptos como los de faktura, antes mencionado, se hacía posible apuntar hacia otros recursos de conformación estética entre los cuales resultaba destacada la fotografía. En el contexto constructivista la fotografía había sido uno de los medios más utilizados para emprender ese corrimiento con respecto a los principios 
netamente formales de la apuesta pictórica abstracta. ${ }^{4}$ Este medio posibilitaba un conjunto de percepciones diferenciadas, las cuales ofrecían la potencialidad técnica de revisar los medios de expresión y las reglas a partir de las cuales se reformulaban las poéticas implicadas en las obras. De acuerdo con una máxima concretista, como aquella formulada por Theo van Doesburg en la "Formación elemental", era necesario apuntar a que "la precisión, la claridad que exigimos de una obra de arte tiene las mismas raíces que la perfección científica o tecnológica que aparece en las prácticas no artísticas de los objetos de nuestro medio" (González García, Calvo Serraller y Marchán Fiz, 2003: p. 265). Según esta perspectiva la fotografía bien podría aparecer como un medio capaz de cumplir con dicho principio impersonal que caracterizaba los modos de producción y reproducción de aquellas prácticas no propiamente artísticas según una preceptiva burguesa.

Considerar el punto de vista fotográfico era por lo tanto pensar desde el punto de vista de la técnica y, si bien este modo de producción de visualidades no fue el predilecto por la corriente concretista aquí señalada, si hacía parte de un conjunto de apuestas de las que participaba esta corriente abstraccionista caracterizada por la multiplicidad de variantes surgidas a lo largo y ancho de Europa y América. El lugar que ocupaba el diseño en estas corrientes resultaba también relevante. Los objetos de la vida cotidiana habían adquirido una peculiaridad que no podía ser desconocida y para la cual la imagen reproductible era también una herramienta destacada.

De todo el escenario concretista en pleno desarrollo y formación a fines de la década del cuarenta, uno de los elementos esenciales a destacar estaba asociado a la idea de la creación de un orden fundado en un racionalismo y la invención objetiva. Junto a esta apreciación, que bien se puede encontrar en la retórica de artistas como van Doesburg, Bill y años mas tarde Tomás Maldonado en la Argentina, ${ }^{5}$ venía aparejada la potencialidad de pensar en otras herramientas objetivas que habilitaran no la reproducción sino la producción de una lógica racional; la fotográfica. Si bien estos artistas no llevaron adelante, de manera particular, una producción sustentada en los mecanismos proyectivos que proporcionaba el pensamiento fotográfico -y las obras fotográficas de Makarius solo aparecerían hasta años más tarde-, es indudable que muchas de estas ideas estéticas fueron modelando gran parte de las concepciones con las cuales los proyectogramas luego encontraron su materialización.

Resulta interesante mencionar que el mecanismo proyectivo con el cual los proyectogramas duplicaban su superficie, participaba de la re-aparición de un universo material trasmutado a partir de los rayos luminosos despedidos por la energía del proyector sobre el cual se disponían los vidrios proyectados. Una suerte de migración lumínica que reconfiguraba materialmente al objeto. La precisión y claridad de la cual pudieron participar estas primeras composiciones se hace evidente en el uso proyectivo que no dejaba lugar a vacilaciones sobre la aparición de las formas. Si bien aquí no había un método establecido para la confección de estas visualidades -como si lo hubo para la pintura concreta- el deseo de una reorganización de los medios a través de una formación elemental se hacía expreso. Vista desde este punto la exploración manifiesta en estas obras estaba asociada a una búsqueda expresiva por medio de las modulaciones de una superficie no homogénea. Soportes de vidrio, recortes, hilos y pegamentos dispuestos en dicha superficie ofrecían texturas variadas que apuntaban, en relación con las ideas estéticas concretas, a una reorganización objetiva en el plano fotosensible.

17 A pesar de que en un sentido estricto muchas de las posturas defendidas por el concretismo no serían necesariamente evidentes en los proyectogramas de Makarius, si 
se dejan ver puntos comunes que echan luz sobre diversas concepciones de la visualidad, la materialidad, la composición y la racionalización del plano, luego superpuestas sobre las luces coloreadas de las formas proyectadas por este artista. Estas materias más que ser cualidades de la sensibilidad, pensadas y llevadas adelante exclusivamente por Makarius, se encarnaban en los proyectogramas como materialidades físicas donde se hacía -y se hace todavía- posible encontrar los tránsitos migrantes de estas ideas adheridas como restos generativos de una estética de la modernidad (Bruno, 2014: p. 55).

Las posibilidades de la máquina constituían para el imaginario mecánico-vanguardista una potencia transformadora que, en su emulación, desataba la alternativa simplificadora. Estas ideas se hacían expresas en los "preliminares" de La Nueva Visión de László Moholy-Nagy que reunía las concepciones bauhausianas luego legadas al escenario artístico suizo por el cual tuvo su tránsito la producción de Makarius. De acuerdo con el lugar concedido a la técnica resultaba llamativa la alineación que proponía el artista húngaro en la primera edición de los Principios básicos de la Bauhaus en 1929. Según sus palabras: "sólo cuando el individuo comprenda que debe funcionar como una entidad productiva más en la comunidad de la humanidad, se acercará a la verdadera comprensión del significado del progreso técnico. No debemos dejarnos cegar por la intrincada trama del asombro productivo; nuestra preocupación esencial debe ser planear acertadamente nuestras vidas" (Moholy-Nagy, 1929 [2018]: p. 29).

En cierto sentido pensar al individuo como una entidad productiva más entre otras, impulsaba una idea de inhumanización que luego el propio Moholy-Nagy rectificaría con la esencialización de la "planeación de la vida". No obstante, la asociación maquínica habilitaba un imaginario de posibilidades técnicas para las cuales la pantalla de proyección fungía como modo de exploración sobre las superficies.

Pensar la fotografía como un puente de enlace entre las artes fue una de las ideas más enriquecedoras en este momento y que encontraba su sistematización en los textos y trabajos del propio Moholy-Nagy. Según su formulación "desde la invención de la película cinematográfica, los pintores se han preocupado por este problema: la proyección, el movimiento y la interpenetración del color y la luz. La fotografía es, indudablemente, un puente de enlace" (Moholy-Nagy, 1929 [2018]: 76). El asunto proyectivo, dinámico y energético era parte de los debates desde los cuales se dirimía el lugar de la fotografía. Medio que, dentro de estas conceptualizaciones, no constituía tanto un modo de reproductibilidad sino de exploración material que llevaba al límite la refracción de la luz y, en ese sentido, las concepciones del espacio-tiempo. El automatismo con el cual se veía el funcionamiento de los procedimientos fotográficos era partícipe del imaginario técnico-objetivo con el cual operaba la conciencia concretista. Desde este punto de vista, los vínculos intermediales habilitaban una reformulación de los principios de comprensión de la expresión visual.

21 El desarrollo, la discusión y la reformulación constante de muchas de estas ideas en la Europa de entreguerras operó como horizonte de interlocución material entre las formas de producción estética y las poéticas a las que ve vio enfrentada la materialidad artefactual elaborada por Makarius. En dicho escenario la fotografía se planteaba como mera posibilidad exploratoria que llevaba hasta las últimas consecuencias muchos de los presupuestos concretos y constructivos a partir de los cuales se expresaba la atmósfera de vanguardia. Para esto, la materialidad fotográfica era por el momento tan solo una herramienta potencial que solo iba encontrar sus capacidades máximas de 
expresión en el contacto con la fotografía propiamente dicha. Así entre Suiza y Francia las materias estéticas de este artista, nacido en Egipto, empezaron a reverberar destellos de una modalidad abstracta concebida desde los principios técnicos más radicales.

\section{Otra alternativa de visión técnica: los vínculos con la fotografía de Werner Bischof}

La impronta documentalista de Werner Bischof, reconocido fotógrafo suizo, no constituyó el punto de encuentro que movilizó la producción de los proyectogramas a pesar de que dicha deriva fotográfica caló muy profundamente en otros tipos de producción técnica que Makarius desarrollaría ya durante su estadía en Buenos Aires. ${ }^{6}$ A pesar de las conocidas visualidades socialmente relevantes que develaba el uso convencional del medio -en una gran cantidad de las fotografías del conocido reportero-, Bischof realizaba también experiencias fotográficas que desafiaban los ordenes de la visión reconocible acercándose así a las experiencias de las vanguardias más radicalizadas de su momento [Fig. 4]. La obsesión por el dinamismo mecánico que había sido expreso en las tendencias cubistas y futuristas anteriores, emergía también en la fotografía como una posibilidad de desafiar los mecanismos de funcionamiento de una imagen extensamente asociada a la huella lisa y llana de lo real.

El contacto más directo con la fotografía que tuvo la poética de Makarius en su itinerancia europea estuvo muy probablemente ligado a los vínculos con Werner Bischof. Los modos a partir de los cuales la fotografía habilitaba otras alternativas expresivas solo podían estar asociados a un cambio radicalizado de medio. Poner en marcha un modo de producción que anulaba cualquier tipo de narrativa, a un medio prácticamente concebido bajo ese fundamento, hacía explícita una apuesta mucho más transformadora de las concepciones al respecto de la superficie y sus capacidades expresivas. El hecho particular que sustentaba la elección abstracta de principios del siglo XX ponía en marcha un tipo de lectura que suponía una condición autorreflexiva. Así, en términos de Rosalind Krauss, "la retícula [fue] una introyección de los límites del mundo en el interior de la obra; [fue] una proyección del espacio que hay dentro del marco sobre sí mismo. [...] una modalidad de repetición, cuyo contenido [era] la naturaleza convencional del propio arte" (2009: p. 33). Trasladar este enunciado a la fotografía suponía que la opción no referencialista de este medio inscribía sus códigos y su gramática material bajo la proyección de su pura superficie.

De acuerdo con esto, el encuentro entre una alternativa pictórica, netamente constructiva y concreta, con la fotográfica, habilitó el despliegue no de la imitación de las formas elementales por medio de recursos fotosensibles, sino de la interrogación sobre otra alternativa de visión que desafiaba la pantalla perceptiva (Krauss, 2009: p. 30). En vez de convertirse en el modelo de una abstracción pictórica, o lo contrario; concebir la abstracción fotográfica suponía abrir la puerta a una interrogación de materialidades otras siempre abiertas a vínculos extensos con la apuesta pictórica. Desde este punto de vista, la alternativa de la abstracción pictórica no constituyó una influencia que en el contacto de Makarius con Bischof habilitó el pasaje a otro tipo de medialidad -intentando imitar con sus recursos una suerte de "iconografía" abstracta-, sino que este pasaje desarticuló un modo de razonamiento netamente pictórico para abrirse a las formas de pensamiento habilitadas por el medio fotográfico. 

era prácticamente fundacional en el devenir estético de la obra de Makarius. Las fuentes de sus vínculos fotográficos se enraizaban en una pregunta por la naturalidad aparente del dispositivo fotográfico y daban rienda suelta a un tipo de individuación técnica (Simondon, 2007) que era propiedad de esta clase de artefactualidades. Sin duda, la materia básica que alimentó este giro fotográfico de Makarius era la luz, energía tiempo espacial (Moholy-Nagy, 1929 [2018]: p. 97) que reconfiguraba las concepciones sobre las formas visibles dispuestas en el plano y doblemente proyectadas sobre superficies. La no unicidad de la concepción de la fotografía por parte de este artista se hacía también evidente en las variadas corporalidades en las que se actualizaba cada composición. De este modo, estos proyectogramas podían bien ser proyectados en un espacio o ser copiados sobre papel blanco y negro (Makarius, 2009: p. 142). Las particularidades cromáticas de varios de los proyectogramas hacían también explícita una conjunción entre la lección constructivista, evidente en obras como las de Lajos Kassák [Fig. 5], al tiempo que implicaba las propiedades energéticas particulares de la interrelación de materias diversas en donde intervenían papeles y químicos.

Las capacidades expresivas de la fotografía se habían extendido hasta sus límites durante la primera mitad del siglo. Las modalidades de las sombras y el fotograma (Baker, 2018: p. 2015) habían desplegado innumerables alternativas que llevaban a cuestionar los modos de inscripción de la propia materia sobre superficies proyectivas modeladas a través de una transformación autónoma de los elementos físicos dispuestos. Al interior de este panorama, los proyectogramas emergieron como propuesta material de una mirada fotográfica desatada al calor de las disputas estéticas de la vanguardia. Su condición netamente técnica habilitó su constitución como núcleo central del cual Makarius nunca se volvió a distanciar.

\section{Conclusiones}

Las materialidades fotográficas encarnadas en los proyectogramas han dejado en claro que sobre su superficie se encarnaron las formas, los sentidos y las prácticas de un itinerario migrante devenido en forma proyectiva. Enfrentarnos a estas fotografías abstractas, luego producidas y difundidas en la Argentina de los cincuenta, ${ }^{7}$ supone repensar aquellos mecanismos e ideas a partir de los cuales se constituyeron. En principio, revisar estos itinerarios estéticos a través de la vida migratoria de las ideas sobre el arte permite señalar el lugar diferenciador que ocupaba la fotografía al interior 
de las poéticas constructivas y concretistas de la vanguardia. La llegada de Makarius a la Argentina, a principios de la década del cincuenta, habilitó el ingreso de una poética saturada de concepciones estéticas radicales que generarían luego un escenario particular para el desarrollo de la fotografía local vinculada con estas preocupaciones materialistas. Imbuidos de las relaciones entre materia, construcción, claridad y fotografía, los proyectogramas vendrían a generar un espacio de interlocución material con otras vías de producción como los fotogramas elaborados años más tarde en el territorio argentino.

Los excesos visuales corporeizados en estas materialidades fotográficas desataban el poder de los objetos para reconfigurar hábitos perceptivos en torno a las concepciones estéticas que se estaban desarrollando en la Argentina de los cincuenta. De esta manera, los proyectogramas operaron como ensamblajes materio-luminosos que daban a ver y a tocar los itinerarios descentrados de una poética que viraba desde la abstracción pictórica hacia la radicalidad fotográfica. En este sentido, las sustancias materiales, formales y estéticas que configuraban estos proyectogramas operaban como entidades vivientes en donde se actualizaban los ideales y discursividades artísticas de la apuesta vanguardista.

31 Antes de convertirse en una mera importación de aquel ethos modernista, el arribo de Makarius y su poética fotográfica desató un modelo posible para las derivas del abstraccionismo y el experimentalismo fotográfico que luego iban a tener un lugar predominante en las décadas de los sesenta y setenta. En este orden de ideas, el despliegue de las concepciones estéticas de la vanguardia, signadas en los modos materiales y compositivos de los proyectogramas, iba a constituir en la Argentina la extensión de los actos poéticos que habían habilitado la producción misma de estos objetos -en un desplazamiento objetivado en estas artefactualidades proyectivas-.$^{8} \mathrm{En}$ función de esta mirada, las superficies de los proyectogramas sugirieron la eficacia del fenómeno fotográfico para poner en ejecución sentidos y concepciones estéticas que excedían los tradicionales del medio fotográfico. Así, de modo evidente, estas artefactualidades dieron cuenta de las capacidades auto-organizativas de la materialidad fotográfica para activar los distintos tránsitos de la poética del artista. En estas obras fotográficas no solo se reunieron los principios estéticos del constructivismo, el concretismo y la alternativa expresiva de la imagen técnica, sino que se convirtieron estos en instancias activas caracterizadas por su vibración permanente sobre la fisicalidad de las obras de Makarius.

De acuerdo con este recorrido, los proyectogramas surgieron como imágenes-contactos que tocaban las tradiciones estéticas más arraigadas en el imaginario moderno occidental. La difusión de las interpretaciones y principios que había formulado la vanguardia europea en distintos marcos culturales, se hacía patente en el contexto argentino por medio de la constitución semántica y material envuelta en las obras allí difundidas. En este sentido, los distintos momentos de los cuales ha intentado dar cuenta este artículo configuraron instancias de determinación de las obras fotográficas de acuerdo con una migración estética que dejaba en claro la movilidad y los desplazamientos de las poéticas y las discursividades con las cuales fueron concebidas. A su vez, estos recorridos permitieron ver distintas temporalidades de una obra físicamente concebida a partir de una multiplicidad de momentos y de ideas en torno al arte. De este modo, los proyectogramas operaron como artefactos que en su dimensión 
puramente material reunieron una pluralidad de principios estéticos devenidos en su forma fotográfica ya en el escenario latinoamericano.

\section{NOTAS FINALES}

1. La fotografía entendida como huella o índice es una de las concepciones sobre el medio más extensamente difundida en los estudios sobre la imagen técnica. Desde esta perspectiva algunos trabajos paradigmáticos han sido los de Roland Barthes (2011); Rosalind Krauss (2009b); JeanMarie Schaeffer (1990); Philippe Dubois (2010), entre muchos otros.

2. Es necesario aclarar en este punto que si bien se hace posible advertir en las concepciones constructivistas sobre la materia un modo de vida propia que excede a los actores, no se puede desconocer el hecho de que "la faktura fue tanto el correlato estético de la industrialización y la ingeniería social que se introdujo en la Unión Soviética tras la Revolución de 1917 como una fase inevitable de tránsito en la transformación del paradigma moderno que tuvo lugar en torno a 1920. [...] la noción de faktura implicaba también una referencia a la ubicación del objeto constructivista y a su interacción con el espectador" (Buchloh, 2004: p. 124).

3. El registro de las prácticas de vanguardia en la Argentina de este contexto es cuantioso. Al considerar los intinerarios migrantes de muchos artistas con experiencias similares a las de Makarius vale la pena mencionar el caso de Gyula Kosice nacido en una comunidad húngara en la Checoslovaquia de la década del 20. Si bien su llegada a la Argentina es temprana, en 1928, su vínculo con el concretismo y las ideas de la Bauhaus se establece a principios de la década del 40, asi como el de artistas como Rhod Rothfuss, Lidy Prati, Edgar Bayley, entre otros. No hay que olvidar también las experiencias vinculadas a la abstracción vanguardista en la Argentina como la revista Arturo, el grupo Madí y la Asociación Arte Concreto-Invención. La obra de Kosice resulta destacable en este artículo en tanto la luz fue un componente esencial de sus esculturas con gas neón a mediados de los 40 .

4. Hay que recordar la dedicación casi exclusiva que hiciron artistas como Aleksandr Ródchenko a la producción fotográfica.

5. Existen numerosos trabajos dedicados al estudio de las poéticas concretas tanto en Argentina como en América Latina. Si bien no dedicada al estudio de la fotografía una de las investigaciones más sistemáticas al respecto es la de María Amalia García en El arte abstracto. Intercambios culturales entre Argentina y Brasil (2011).

6. Cabe mencionar al respecto los trabajos más conocidos y difundidos de Makarius en la Argentina Buenos Aires y su gente (1960) y Buenos Aires mi ciudad (1963).

7. Estos proyectogramas fueron presentados solo una vez en la Galería Galatea ubicada en el entrepiso de la librería Galatea (Makarius, 2009: p. 142).

8. Esta idea del despliegue como extensión del acto del pliegue es desarrollada por Deleuze pensando de modo particular en la lógica del Barroco (2014: p. 51).

BAKER, Simon (2018), “1940-1960 Photography's Sense of Abstraction”, en: BAKER, Simon; DE

L'ECOTAIS, Emmanuelle; MAVLIAN, Shoair, Shape of Light. 100 Years of Photography and Abstract Art. D.A.P., London.

BARTHES, Roland. (2011), La cámara lùcida. Nota sobre la fotografía. Traducción de Jaoquim SalaSanahuja. Paidós, Barcelona. 
BENNETT, Jane (2010), Vibrant Matter. A political ecology of things. Duke University Press, Durham. BRUNO, Giuliana (2014), Surface. Matters of aesthetics, materiality, and media. University of Chicago Press, Chicago.

BUCHLOH, Benjamin, H. D. (2004) "De la faktura a la factografía", en: Formalismo e Historicidad. Modelos y métodos en el arte del siglo XX. Akal, Madrid.

COOLE, Diana y FROST, Samantha (2010), New Materialisms. Ontology, Agency, and Politics.Duke University Press, Durham.

DE MICHELI, Mario (2012). Las vanguardias artísticas del siglo XX. Alianza, Madrid.

DELEUZE, Gilles (2014), El pliegue. Leibniz y el Barroco. Paidós, Buenos Aires.

DELEUZE, Gilles \& GUATTARI, Félix (2004), Mil Mesetas. Capitalismo y esquizofrenia. Pre-Textos, Valencia.

DUBOIS, Philippe (2010), El acto fotográfico. De la representación a la recepción. Paidós, Buenos Aires. DUROZOI, Gérard (1997), Diccionario Akal de arte del Siglo XX. Madrid: Akal.

FLUSSER, Vilém (2014), Para una filosofía de la fotografía. La marca, Buenos Aires.

GARCÍA, Maria Amalia (2011), El arte abstracto. Intercambios culturales entre Argentina y Brasil. Siglo XXI, Buenos Aires.

GONZÁLEZ GARCÍA, Angel; CALVO SERRALLER, Francisco y MARCHÁN FIZ, Simón (2003), Escritos de arte de vanguardia 1900-1945. Istmo, Madrid.

IOVINO, Serenella y OPPERMANN, Serpil (2018), "Ecocrítica material: materialidad, agencia y modelos narrativos." Traducción de Guadalupe Lucero y Noelia Billi, Pensamiento de los confines, $\mathrm{n}^{\circ}$ 31-32, primavera-verano, pp. 215-227.

KOPYTOFF, Igor (1991), “La biografía cultural de las cosas: la mercantilización como proceso", en: APPADURAI, Arjun (ed.), La vida social de las cosas. Perspectiva cultural de las mercancías. Grijalbo, México.

KRAUSS, Rosalind (2009), "Retículas", en, La originalidad de la Vanguardia y otros mitos modernos. Alianza, Madrid, pp. 23-37.

KRAUSS, Rosalind. (2009b)“Notas dobre el índice. Parte 1.” La originalidad de la vanguardia y otros mitos modernos. Alianza Editorial, Madrid.

KRIEBEL, Sabine. T. (2006), “Theories of photography. A short history”, en: ELKINS, James (ed.), Photography Theory. Routledge, New York.

MAKARIUS, Carlos Marcos (2009), Sameer Makarius. Retrospectiva artística 1946-2009. Ediciones del autor, Buenos Aires.

MOHOLY-NAGY, László (2018), La nueva visión. Principios básicos del Bauhaus. Ediciones Infinito, Buenos Aires.

SCHAEFFER, Jean-Marie (1990). La imagen precaria. Del dispositivo fotográfico. Cátedra, Madrid. SIMONDON, Gilbert (2007), El modo de existencia de los objetos técnicos. Prometeo, Buenos Aires. WITZGALL, Susanne (2014), "Power of Materia/Politics of Materiality - an Introduction”, en: WITZGALL, Susanne y KERSTIN Stakemeirt (eds.), Power of Material/Politics of Materiality. diaphanes, Berlin, pp. 14-15. 


\section{RESÚMENES}

Este trabajo pretende analizar y definir a los proyectogramas de Sameer Makarius, producidos en la década del 50 en Argentina, como materialidades fotográficas vibrantes y migrantes que no solo son portadoras de significados, sino que los generan autopoiéticamente sobre su superficie. En este sentido, será necesario reconstruir las marcas, en su producción fotográfica abstracta, de sus itinerarios en la Europai Iskola en Budapest, su contacto en Zúrich con el constructivismo y las derivas bauhausianas y sus posteriores vínculos fotográficos con Werner Bischof. Estos trayectos darán cuenta no tanto de la experiencia migratoria del artista, sino de la materialización de un recorrido estético que se hace visible y tangible en la propia materialidad de sus fotografías.

Ce travail vise à analyser et à définir les proyectogramas de Sameer Makarius, réalisés dans les années 1950 en Argentine, comme des matérialités photographiques vibrantes et migratoires qui non seulement portent un sens, mais les génèrent aussi de manière autopoïétique à leur surface. En ce sens, il faudra reconstruire les traces, dans sa production photographique abstraite, de ses itinéraires à l'Europai Iskola de Budapest, de son contact à Zurich avec le constructivisme et les dérives bauhausiennes et de ses liens photographiques ultérieurs avec Werner Bischof. Ces voyages ne rendront pas tant compte de l'expérience migratoire de l'artiste, mais plutôt de la matérialisation d'un parcours esthétique qui devient visible et tangible dans la matérialité même de ses photographies.

\section{ÍNDICE}

Mots-clés: Sameer Makarius, constructivisme, abstraction photographique, matérialité photographique, nouveaux matérialismes.

Palabras claves: Sameer Makarius, constructivismo, abstracción fotográfica, materialidad fotográfica, nuevos materialismos

\section{AUTOR}

\section{JULIANA ROBLES DE LA PAVA}

CONICET/ Centro de Investigación en Arte, Materia y Cultura IIAC-UNTREF/ Universidad de Buenos Aires, Argentina 